\title{
FANCM-family branchpoint translocases remove co-transcriptional R-loops
}

\author{
Charlotte Hodson $^{1 \wedge}$, Julienne J O’Rourke ${ }^{1,2}$, Sylvie van Twest ${ }^{1}$, Vincent J Murphy ${ }^{1}$, Elyse Dunn ${ }^{1}$ \\ and Andrew J Deans ${ }^{* 1,2}$.
}

${ }^{1}$ Genome Stability unit, St. Vincent's Institute of Medical Research, Fitzroy, Victoria, Australia

${ }^{2}$ Department of Medicine (St Vincent's Health), University of Melbourne, Fitzroy, Victoria, Australia

*Corresponding author adeans@svi.edu.au

^current address: Astex Pharmaceuticals, 436 Cambridge Science Park, Milton Road, Cambridge, United Kingdom.

\begin{abstract}
Co-transcriptional R-loops arise from physiological or aberrant stalling of RNA polymerase, leading to formation of stable DNA:RNA hybrids. Unresolved R-loops can promote genome instability. Here, we show that the Fanconi anemia- and breast cancer-associated FANCM protein can directly unwind DNA-RNA hybrids from co-transcriptional R-loops in vitro. FANCM processively unwinds both short and long R-loops, irrespective of sequence, topology or coating by replication protein A. R-loops can also be unwound in the same assay by the yeast and bacterial orthologs of FANCM, Mph1 and RecG, indicating an evolutionary conserved function. Consistent with this biochemical activity of FANCM, we show that FANCM deficient cells are sensitive to drugs that stabilize R-loop formation. Our work reveals a mechanistic basis for Rloop metabolism that is critical for genome stability.
\end{abstract}




\section{Introduction}

2 R-loops form when RNA anneals within duplex DNA, and displaces a corresponding single-

3 strand DNA (ssDNA) patch. R-loops can arise directly, from transcription of difficult to transcribe

4 regions, or by enzyme driven integration of RNA, such as R-loops created by the Cas9 protein

5 during CRISPR (Ginno et al, 2012, Szczelkun et al, 2014). Persistent R-loops can be a threat to

6 genome stability because the displaced ssDNA within an R-loop is prone to cleavage by

7 nucleases (creating DNA breaks)(Arudchandran et al, 2004), recombination with distant DNA

8 sequences (creating chromosome rearrangements)(Huertas \& Aguilera, 2003) and atypical

9 modification by ssDNA viral defence proteins such as APOBEC enzymes (creating base

10 substitutions)(Sollier \& Cimprich, 2015).

11 Several studies have shown DNA replication-dependent genome instability is partially

12 prevented when the rate of transcription is reduced, indicating that R-loops cause DNA damage

13 predominantly during S phase (Hamperl et al, 2017, Helmrich et al, 2011, Schwab et al, 2015).

14 In particular, the Fanconi anemia (FA) DNA repair pathway is activated by R-loop accumulation,

15 culminating in formation of monoubiquitinated FANCD2 at R-loop rich regions (Garcia-Rubio et

16 al, 2015, Madireddy et al, 2016, Schwab et al, 2015). As FANCD2 monoubiquitination is

17 normally activated by direct barriers to the replication machinery (such as DNA double strand

18 breaks or interstrand crosslinks) (Deans \& West, 2011), R-loops most likely also activate the FA

19 pathway by blocking DNA replication. In support of this hypothesis, accumulation of

20 monoubiquitinated FANCD2 during normal replication (but in the absence of exogenous DNA

21 damage) is suppressed by over-expression of RNAseH1 (Madireddy et al, 2016, Schwab et al, 
22 2015). This nuclease specifically removes DNA:RNA hybrids in the nucleus (Nakamura et al,

23 1991).

24 FANCM is a component of the FA pathway that is essential for activation of FANCD2

25 ubiquitination (Coulthard et al, 2013), but also has additional FA pathway-independent

26 functions. These include direct remodeling of DNA replication fork structures, recruitment of

27 DNA repair complexes, activation of the ATR checkpoint pathway and suppression of meiotic

28 crossovers (Collis et al, 2008, Crismani et al, 2012, Deans \& West, 2009, Gari et al, 2008a). We

29 recently reported elevated formation of R-loops in FANCM-defective cells (Schwab et al, 2015).

30 This was not because of increased transcription, but because of failure to properly remove R-

31 loops (Schwab et al, 2015). Similarly, R-loops accumulate at telomeres after FANCM depletion,

32 particularly in cells that utilize the ALT pathway of telomere maintenance(Pan et al, 2017). As

33 such, FANCM may also prevent accumulation of DNA:RNA hybrids by the TERRA long non-

34 coding RNA, which is essential for maintenance of ALT (Arora et al, 2014).

FANCM is a functional ortholog of the yeast Mph1 and Fml1 branchpoint translocase proteins

36 (Whitby, 2010). Like these enzymes, FANCM contains an N-terminal SF2 helicase domain whose

37 ATPase activity is activated only by branched DNA molecules (such as those found at stalled

38 DNA replication or transcription bubbles)(Coulthard et al, 2013), and can translocate replication

39 forks and Holliday junction DNA structures. Here we show for the first time that FANCM, and its

40 yeast homolog Mph1, are also efficient in R-loop processing. Like for the bacterial RecG protein

41 (Hong et al, 1995, Vincent et al, 1996), this function depends upon ATP hydrolysis and involves

42 branch migration, to directly remove RNA trapped in co-transcriptionally formed R-loops. 
bioRxiv preprint doi: https://doi.org/10.1101/248161· this version posted January 15,2018 . The copyright holder for this preprint (which was not certified by peer review) is the author/funder, who has granted bioRxiv a license to display the preprint in perpetuity. It is made available under aCC-BY-NC-ND 4.0 International license.

43 FANCM can unwind R-loops of different size and sequence, including a highly stable R-loop

44 formed by transcription across a telomeric repeat. Importantly, we also show that FANCM

45 deficient cells, but not those lacking another FA group member, are highly sensitive to small

46 molecule drugs that promote R-loop formation. 


\section{Results}

48 In vitro unwinding of co-transcriptional R-loops by the FANCM-FAAP24 complex

49 We previously showed that FANCM can unwind DNA:RNA hybrids within a homologous duplex

50 (Schwab et al, 2015), a property it shares with other human enzymes such as BLM and

51 replicative helicases (Chang et al, 2017, Shin \& Kelman, 2006). Because this type of structure

52 may not accurately represent the formation of a co-transcriptional R-loop, we set about

53 establishing a more sophisticated substrate that contains the high GC skew, closed triplex

54 structure and longer length of native R-loops (Ginno et al, 2013). To do this we used a pUC19

55 plasmid containing the mouse immunoglobulin class switch recombination sequence (s $\mu$

56 region) in between a T7 promotor and terminator (Supplemental Figure 1a). Using T7

57 polymerase and ${ }^{32} \mathrm{P}$-UTP we generated co-transcriptional R-loops using techniques previously

58 described by Roy et al (Roy et al, 2008), where the formation of R-loops can be measured by

59 both a change in plasmid mobility, and retention of the radiolabeled nascent RNA (Figure 1a).

60 Treatment with RnaseH but not Rnase A led to loss of the R-loop structure on the gel, and loss

61 of signal on autoradiographs, confirming the presence of RNA-DNA hybrids within the plasmids

62 (Figure 1b lane4). RNase $\mathrm{H}$ degraded the RNA molecule down to nucleotide sized fragments,

63 however addition of FANCM (in heterodimer with its stabilization partner FAAP24) led to

64 release of the RNA transcript without degradation (Figure 1c). This process was ATP dependent:

65 the R-loop remained intact when wild-type FANCM:FAAP24 was added in the absence of ATP

66 (Figure 1c, lane 3) or when the ATPase dead FANCM mutant complex FANCM ${ }^{\text {K117R }}$-FAAP24 was

67 used (Figure 1c). We also tested whether other members of the FA pathway could act on R- 
68 loops, given that in vivo studies suggest the entire FA pathway (Supplemental Figure 2a) may be

69 required for R-loop regulation (Garcia-Rubio et al, 2015, Schwab et al, 2015). No component of

70 the FA core complex of proteins, or the FANCI:FANCD2 heterodimer had any direct effect on co-

71 transcriptional R-loops in our assay. Under these experimental conditions only the FANCM-

72 FAAP24 complex can unwind an R-loop structure. (Supplemental Figure 2b).

73 FANCM-FAAP24 unwinding of co-transcriptional R-loops is processive and not blocked by RPA

74 binding

75 In vivo, ssDNA displaced within an R-loop is most likely bound by ssDNA binding proteins such

76 as Replication Protein A (RPA), to protect it from attack by DNA modifying enzymes (Nguyen et

77 al, 2017). To determine whether FANCM-FAAP24 could still unwind R-loops in which the

78 displaced strand is coated in RPA filament, we incubated plasmid R-loops with molar excess of

79 RPA for 15 minutes prior to adding FANCM-FAAP24. As expected, a uniform shift in

80 electrophoretic mobility was observed when the displaced DNA strand in the R-loop became

81 bound by RPA (Figure 2a). After addition of FANCM-FAAP24, 70\% of the RPA bound R-loops

82 were unwound within 5 minutes, whereas $92 \%$ of uncoated R-loops were unwound. By 10

83 minutes, almost all of the uncoated R-loops and approximately $85 \%$ of RPA bound R-loops were

84 unbound (Figure $2 b-c$ ). This observation was not due to addition of extra protein to the reaction

85 because high concentrations of Bovine Serum Albumin (BSA) did not cause an effect

86 (Supplemental Figure 3). Together, these data suggest FANCM-FAAP24 acts in a processive

87 manner on both naked and RPA-coated R-loops, and that RPA has a slight inhibitory effect on

88 the unwinding ability of FANCM. 


\section{FANCM-FAAP24 can unwind R-loops of different topology}

91 Topological changes in DNA occur during the formation of R-loops, because the bound RNA

92 creates underwound or overwound (supercoiled) regions. Topological effects may both

93 promote R-loop formation during transcription (El Hage et al, 2010, Powell et al, 2013) or

94 prevent R-loop removal, including by FANCM or other enzymes. To test this, we first assessed

95 whether our purified plasmid R-loops were stable upon induction of topological change. As

96 linearization removes all covalent topology from DNA, we treated our plasmid R-loops with

97 restriction enzymes EcoRI and HindIII. We found that linearization had no effect on R-loop

98 stability (Figure 3a). Second, R-loops were also stable in a un-super-coiled covalently closed

99 circular (ccc) plasmid generated by E.coli Topo1 or human Topoisomerase III :RMI1:RMI2

100 complex, with which FANCM associates in cells (Deans \& West, 2009) (Figure 3a). Together,

101 these data show that once formed, transcriptional R-loop structures are stable regardless of

102 changes in DNA topology. These observations and others (Wilson-Sali \& Hsieh, 2002) support

103 the idea that type I topoisomerase role in transcription is in prevention of R-loop formation, but

104 not the direct removal of RNA trapped within an R-loop.

105 We next tested the ability of FANCM-FAAP24 to unwind the topologically distinct R-loop forms.

106 In time course assays, FANCM showed no preference in activity towards either supercoiled,

107 linear or ccc R-loops (Figure 3b-c) unwinding all at essentially equal rates. This suggests that

108 DNA topology does not affect R-loop unwinding activity of FANCM against a native R-loop

109 structure. 
112 R-loops accumulate in different regions of the genome including highly transcribed genes, GC-

113 skewed promoters and telomeric repeats (Arora et al, 2014, Ginno et al, 2012, Powell et al,

114 2013). To test whether R-loop processing by FANCM showed any sequence preference, we

115 tested several sequences that were previously demonstrated to be strongly R-loop prone

116 (Ginno et al, 2012). These sequences include the human APOE or SNRPN and mouse Airn

117 genomic loci, which we cloned into our in vitro R-loops test plasmid (Supplementary Figure 1).

118 These regions were assessed for their percentage of GC skew using genskew.csb.univie.ac.at

119 (Figure 4a). All were unwound rapidly and efficiently by FANCM:FAAP24 (Figure 4a). FANCM

120 could also remove R-loops formed by transcription through the telomeric repeat sequence,

121 otherwise known as TERRA transcripts (Figure 4b). These R-loops have previously been shown

122 to have a strong G-quadraplex forming ability (Martadinata \& Phan, 2013), suggesting that

123 FANCM's R-loop processing capability extends to R-loops that contain G-quadraplexes either

124 within the displaced strand or between the RNA and the displaced strand (Arora et al, 2014),

125 and supports a role for FANCM in the TERRA-dependent maintenance of telomeres by the ALT

126 pathway of telomere maintenance (Lee et al, 2014, Pan et al, 2017).

127 As R-loops of greater than 600bp can be detected in a cellular context (Ginno et al, 2012) we

128 examined whether FANCM-FAAP24 could processively unwind R-loops containing different

129 lengths of RNA. To do this we generated a plasmid containing 1148bp of repeats of the

130 immunoglobulin class switch s $\mu$ sequence (Supplementary Figure 1) downstream of a T7 
131 promoter. We compared the size of RNA trapped within these R-loops to those found in the

132 standard R-loop (consisting of a single s $\mu$ repeat of $143 \mathrm{bp}$ ) by subjecting the purified R-loops to

133 Urea-PAGE. Denaturation revealed multiple RNA species of different lengths within the

134 population of R-loops (Fig.4c). One explanation for this observation is that RNase A could cleave

135 unpaired single strand regions within a longer R-loop, hence making the actual hybrid pieces

136 appear shorter. Alternatively, T7 RNA polymerase could be stalling stochastically at different

137 points along the template. Importantly though, the RNA fragments between the standard and

138 long R-loops gave different average sizes of $\sim 150$ and $\sim 300$ nucleotides respectively (Figure 4c).

139 We could therefore compare the rate of unwinding on R-loops of similar sequence but different

140 length. Using the defined conditions of this assay FANCM-FAAP24 can unwind $100 \%$ of short

141 plasmid R-loops within 5 minutes, with 55\% unwinding occurring within the first minute

142 (Figure $4 d$ ). In contrast FANCM-FAAP24 takes 10 minutes to achieve $~ 85 \%$ unwinding of longer

143 plasmid R-loops, a similar rate of unwinding when corrected for length (Figure 4d).

144 Collectively, these data further support the concept that FANCM:FAAP24 traverses long tracks

145 of DNA without dissociation (i.e. processivity), to remove RNA molecules trapped within

146 extended R-loop sequences.

148 R-loop displacement is a conserved feature of FANCM family proteins

149 FANCM protein is a 230kDa protein, with an N-terminal translocase domain, a C-terminal ERCC4

150 structure specific DNA binding domain, and multiple protein:protein interaction domains that 
151 recruit additional DNA repair factors (Blackford et al, 2013, Coulthard et al, 2013, Deans \&

152 West, 2009) (Figure 5a). Only the N-terminal translocase domain is conserved in homologs from

153 lower eukaryotes, such as Mph1 from Saccharomyces cerevisiae, and Fml1 from S. pombe

154 (Whitby, 2010). RecG proteins are thought to be the closest relatives of FANCM/Mph1/Fml1 in

155 bacteria (Gari et al, 2008a, Sun et al, 2008). To test whether R-loop unwinding is a conserved

156 feature of these "FANCM family" members we purified recombinant S.cerevesae Mph1

157 S.pombe Fml1 or Thermatoga maritima RecG and tested their activity against our co-

158 transcriptional R-loops (Figure 5b). RecG has previously been demonstrated to unwind

159 synthetic linear R-loops (Vincent et al, 1996) but Mph1 and Fml1 have never been tested.

160 Further data, collected using a FANCM fragment (aa 1-800), revealed the N-terminal conserved

161 translocase domain of FANCM is sufficient for in vitro R-loop removal (Figure $5 c$ ). All of these

162 enzymes displaced the co-transcriptional R-loops with similar activity, indicating a conserved

163 function of FANCM-family proteins.

164 FANCM protein (and Mph1 and RecG (McGlynn et al, 1997, Prakash et al, 2009)) can also

165 unwind D-loops, which share structural similarities with R-loops (see Discussion). D-loop

166 formation is an intermediate in DNA repair by homologous recombination which requires

167 RAD51 or RecA recombinase. In addition to FANCM-family members, the RecQ helicase BLM

168 (mutated in Bloom's Syndrome) can unwind D-loops (Bachrati et al, 2006). We therefore tested

169 BLM for its ability to unwind co-transcriptional R-loops. We carried out the assay with

170 increasing amounts of BLM (Figure $5 \mathrm{~d}$ ). While BLM protein could unwind a very small fraction of

171 the plasmid R-loops at high molar ratios of enzyme to plasmid (highest concentration 40nM, to

172 1nM substrate), it did this very slowly compared to FANCM:FAAP24, which rapidly unwound R- 
173 loops at stoichiometric and sub-stoichiometric concentrations (1nM for Figure 5d). In contrast

174 to its much lower activity towards R-loop substrates, BLM was as efficient as FANCM in assays

175 using a plasmid D-loop substrate (Supplemental Figure 4). These data suggest that BLM is

176 capable of unwinding R-loop structures, but unlike for FANCM, they are not its preferred

177 catalytic substrate.

178 FANCM KO cells but not FANCL KO cells are sensitive to agents that induce R-loop

179 stabilization

180 We recently demonstrated that FANCM knockout cells, or those expressing a translocation

181 deficient FANCM ${ }^{\mathrm{K} 117 \mathrm{R}}$ mutant protein, accumulate excessive R-loops under normal cell culture

182 growth conditions (Schwab et al, 2015). Several chemicals have also been shown to increase R-

183 loop prevalence, each by a different mechanism. These include inhibitors of the spliceosome

184 (that promote R-loops through retention of intronic sequences), topoisomerase 1 inhibitors

185 such as topotecan (that promote R-loops by stalling transcription), and reactive aldehydes

186 (unknown mechanism) (Powell et al, 2013, Schwab et al, 2015, Wan et al, 2015). We used

187 isogenic FANCM KO, FANCL KO or parental HCT116 cells (previously characterized by Wang et al

188 (Wang et al, 2013)) and tested their sensitivity to increasing concentrations of these R-loop

189 promoting compounds. We found that FANCM deficient cells are particularly sensitive to

190 topotecan and the spliceosome inhibitor pladienolide B, while FANCL-deficient cells are not

191 (Figure 6a-b). Both FANCM and FANCL deficient cells are exquisitely sensitive to acetyl

192 aldehyde, which also generates DNA interstrand crosslink damage in addition to R-loop

193 accumulation. 
194 Importantly, sensitivity to both topotecan and pladienolide B correlated with an inflection point

195 in total cellular R-loop levels in response to these drugs. This was measured by slot blot of

196 genomic DNA probed with anti-DNA:RNA hybrid monoclonal antibody S9.6 (Figure 6c-d). R-loop

197 levels and LD50 dosage were highly related, and suggests that cellular viability in response to

198 these compounds correlates with a threshold R-loop level. This maximum tolerated level is

199 reached with lower doses of either topotecan or pladienolide B in FANCM-deficient cells. This

200 result indicates that R-loop metabolism requires FANCM activity independent of the other FA

201 ICL repair proteins, to catalytically unwind R-loops formed under both physiological and drug-

202 induced conditions. 


\section{Discussion}

204 Even though FANCM contains a SF2 helicase domain, exhaustive investigations have never

205 uncovered a direct helicase activity of the protein against any DNA substrate (Coulthard et al,

206 2013, Gari et al, 2008a, Gari et al, 2008b, Meetei et al, 2005, Mosedale et al, 2005, Whitby,

207 2010, Xue et al, 2008). Instead, FANCM is thought to act on junctions in DNA as a branch point

208 translocase (Gari et al, 2008a, Gari et al, 2008b). In this manner, it utilizes its ATP-dependent

209 motor to reanneal DNA and further displace annealed strands ahead of the junction, without

210 directly acting to unwind DNA like a helicase. This has been proposed for two different DNA

211 structures: (i) stalled replication forks, whereby the annealing of nascent DNA strands by

212 FANCM catalyzes replication fork reversal and the formation of a chicken foot structure and (ii)

213 during recombination and D-loop formation, FANCM can catalyze displacement of the invading

214 structure (Figure 7). Both of these activities have also been described for yeast Mph1 and

215 bacterial RecG (McGlynn et al, 1997, Muller \& West, 1994, Prakash et al, 2009). We propose a

216 similar function for FANCM, Mph1 and RecG at R-loops at stalled transcription complexes. The

217 branchpoint of all three structures, and the catalytic mechanism required for their

218 translocation, is identical. In the case of stalled replication forks, FANCM creates the substrate

219 necessary for resumption of replication (Gari et al, 2008a). But for D-loops and R-loops, FANCM

220 is acting to suppress illegitimate recombination and/or barriers to DNA replication and

221 transcription.

222 R-loop branch migration does not appear to be a general property of all translocases and

223 helicases. For example, another SF2 helicase, BLM, can displace RNA from the R-loop, but only 
224 weakly when used at high concentration; similar to observations made for the bacterial enzyme

225 RuvAB (Vincent et al, 1996). Like RuvAB, BLM is able to act to directly unwind DNA:RNA

226 heteroduplexes constructed from synthetic oligonucleotides (Chang et al, 2017, Popuri et al,

227 2008), but these contained heterologous base-pairing, or extensive ssDNA regions that are not

228 present in "native" co-transcriptional R-loops. The weak activity of BLM at high enzyme to

229 substrate ratios (40:1, Figure $5 \mathrm{~d}$ ) on co-transcriptional R-loops, is probably the result of

230 "accidental" helicase activity with the R-loop as the protein moves along double stranded DNA

231 (Cheok et al, 2005), rather than the direct branch migration mechanism proposed for FANCM,

232 Fml1, Mph1 and RecG. Future work should also compare the activity of FANCM to that of other

233 proposed R-loop metabolizing enzymes such as Senataxin (Yuce \& West, 2013), Aquarius

234 (Sollier et al, 2014) and DHX9 (Chakraborty \& Grosse, 2011). It should be noted that none of

235 these enzymes in purified form have been directly tested for activity on co-transcriptional R-

236 loops.

237 But what is the nature of R-loops that are acted upon by FANCM? R-loops can form at multiple

238 different loci. Indeed, mathematical modeling suggests that every transcribed region is able to

239 form an R-loop, but that increased observation at some loci comes from the fact that particular

240 sequences are more prone to their formation, such as G-rich sequences (Belotserkovskii et al,

241 2017). Another consequence paradoxically, is that within a cell population, highly transcribed

242 genes are more likely to be discovered in an R-loop-bound, arrested state. In this study, we

243 have shown that FANCM can displace RNA from all co-transcriptional R-loops tested, including

244 those that are long and those with very high G-content. FANCM therefore has the potential to

245 act upon any R-loop in the genome. This might include R-loops required to initiate class switch 
246 recombination at the immunoglobulin heavy chain locus in activated B cells, which regulates

247 immune function and occurs during G1 phase of the cell cycle (Schrader et al, 2007). Some FA

248 mouse models show minor class switching defects (Nguyen et al, 2014), although Fancm-

249 deficient mice have not been tested in this respect (Singh et al, 2009). We favor the hypothesis

250 that FANCM's R-loop regulation activity concerns their removal ahead of, or encountered by,

251 the replication fork. This is because overwhelming evidence points to a role for the Fanconi

252 anemia pathway in DNA damage during S phase (Deans \& West, 2011) and the fact that FANCM

253 protein is enriched in chromatin at sites of ongoing replication (Blackford et al, 2013, Castella et

254 al, 2015). But DNA:RNA hybrids were also recently shown to form by transcription from dsDNA

255 breaks during resection, when RNA polymerases become loaded onto broken DNA ends (Ohle

256 et al, 2016). FANCM may play some role in displacing such hybrids in prevention of over-

257 resection, another phenotype of FANCM-deficient cells (Blackford et al, 2013).

258 Finally, the maintenance of telomeres is also regulated by R-loops in some cancers (Azzalin et

259 al, 2007). TERRA transcripts are produced by transcription of the C-rich telomeric DNA strand

260 and are essential for the ALT mechanism of telomere maintenance by recombination. FANCM is

261 necessary for ALT (Pan et al, 2017), and it is possible that this is because it acts on TERRA

262 transcripts to permit telomere replication or somehow regulate telomere recombination. Our in

263 vitro experiments demonstrate that FANCM displaces the G-quadraplex stabilized TERRA

264 transcripts as efficiently as it acts on promoter- or switch-region- based R-loops.

265 While several physiological R-loops may be targeted by FANCM activity, it is also clear that

266 chemically induced (or pathological) R-loops accumulate more rapidly, and for longer periods, 
267 in FANCM-deficient cells (Figure 6). In particular, R-loop promoting inhibitors of topoisomerase

2681 or splicing promote R-loop accumulation at lower concentrations in FANCM-knockout cells,

269 and this correlates with increased cell death induced by these drugs. Camptothecin sensitivity

270 was also observed in cells from Fancm-deficient mice (Bakker et al, 2009), Mph1 deficient yeast

271 (Scheller et al, 2000) and RecG deficient bacteria (Sutherland \& Tse-Dinh, 2010). Such sensitivity

272 is not a common property of homologous recombination deficiency, but is seen for a subset of

273 HR proteins that also play a role in R-loop metabolism, such as BRCA1 and BRCA2 (Bhatia et al,

274 2014, Hill et al, 2014). Recent evidence suggests that transcription replication collisions

275 promoted by splicing inhibitors or topoisomerase poisons could provide a major mechanism for

276 the therapeutic action of these drugs (Sollier \& Cimprich, 2015). As such, FANCM-deficiency or

277 FANCM-overexpression could modulate the tumour and normal cellular response to these

278 drugs in clinical use.

279 In conclusion, our biochemical reconstitution of co-transcriptional R-loop formation has

280 established branch point translocation as a major mechanism of R-loop release. Given the

281 emerging role of R-loops in cancer (Sollier \& Cimprich, 2015, Stork et al, 2016), it is possible that

282 a defect in FANCM mediated R-loop metabolism is directly responsible for the tumour prone

283 phenotype of FANCM-associated Fanconi anaemia (homozygous mutations) and familial breast

284 cancer (heterozygous carriers). The highly processive in vitro activity of FANCM, and strong R-

285 loop phenotype after treatment with various chemotherapy drugs is consistent with an

286 important role for processing of R-loops by FANCM in human disease. 


\section{Methods}

\section{Co-transcriptional R-loop plasmid design and construction}

290 Co-transcriptional R-loop sequences for the human APOE or SNRPN promoter sequences or

291 murine $\mu$-switch repeat or AIRN promoter sequences were synthesized with a 5'-flanking T7

292 promotor and 3'-T7-terminator sequence and cloned into the EcoRI and HindIII sites of pUC19

293 (followed by sequence verification) by General Biosystems (Sequences are provided in

294 Supplemental Figure 3). To generate the longer R-loop plasmid (pUC19 SR long), successive

295 rounds of restriction cloning was undertaken to concatermerize the $\mu$-switch repeat through

296 repetitive subcloning of Avrll/HindIII digested fragments into Spel/HindIII digested pUC19-SR.

297 Plasmids were transformed into NEB 10-beta cells (NEB), plated and midi prepped (Qiagen).

298 DNA concentration was established by nanodrop. R-loop forming plasmids have been deposited

299 at Addgene. pcDNA6-Telo and TeloR contain a $0.8 \mathrm{~kb}$ fragment of human telomeric repeat

300 cloned downstream of a T7 promoter (Arora et al, 2014).

\section{$301 \quad$ R-loop generation and purification}

$3022 \mu \mathrm{g}$ of plasmid DNA was incubated in a final reaction volume of $200 \mu$ l containing $1 \times$ T7

303 polymerase reaction buffer (NEB), 25 units of T7 polymerase (NEB), $2.25 \mathrm{mM}$ of each nucleotide

304 CTP, GTP, ATP and 825nM UTP-a- ${ }^{32} \mathrm{P} 3000 \mathrm{Ci} / \mathrm{mmol}$ (Perkin Elmer) for 1 hour at $37^{\circ} \mathrm{C}$. The

305 reaction was stopped by heat denaturation at $65^{\circ} \mathrm{C}$ for $20 \mathrm{mins} .100 \mu \mathrm{l}$ of $1.05 \mathrm{M} \mathrm{NaCl}$ and $0.03 \mathrm{M}$

$306 \mathrm{MgCl}_{2}$ buffer was added to each reaction plus $2.5 \mu \mathrm{g}$ of Rnase A (EpiCentre) for $1 \mathrm{hr}$ at $37^{\circ} \mathrm{C}$. R-

307 loops where then purified by $2 x$ phenol/chloroform using phase lock tubes (Quanta Bio),

308 precipitated in a final concentration of $0.3 \mathrm{M} \mathrm{Na}$ Acetate and $70 \%$ ethanol at $-20^{\circ} \mathrm{C}$ overnight.

309 Next day the samples were centrifuged at $13,000 \times g$ in table top centrifuge for $30 \mathrm{~min}$. 
310 Supernatant was removed and samples were washed with $70 \%$ ethanol and centrifuged for a

311 further $10 \mathrm{~min}$. Supernatant was removed and pellets were left to air dry. R-loops were

312 resuspended in $10 \mathrm{mM}$ Tris $\mathrm{pH} 8$, then ran through $2 \times \mathrm{S}-400$ columns (GE Healthcare) to remove

313 unincorporated nucleotides, quantified using nanodrop and stored at $4^{\circ} \mathrm{C}$.

314 Protein Purification

315 The following were purified as previously described: FLAG-FANCM-FAAP24 and FLAG-

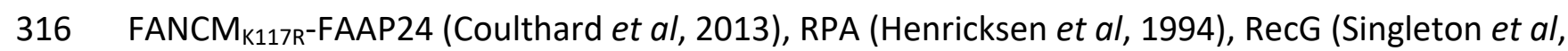

317 2001) (a kind gift of Steve West, Francis Crick Institute), Flag-BLM, Flag-Mph1 and Flag-

318 Topoisomerase III $\alpha$-RMI1-RMI2 expression vectors were cloned into pFL or pUCDM baculovirus

319 vectors and subsequently integrated into the Multibac Bacmid (Berger et al, 2004). For these

320 proteins, 1 L High 5 Trichoplusia ni cells $\left(1 \times 10^{6} / \mathrm{ml}\right.$, Invitrogen) were infected with virus

321 (MOI=2.5). Cells were harvested 72 hours after infection at $500 \times g, 4^{\circ} \mathrm{C}$ and pellets washed with

322 1xPBS. Cells were lysed on ice in $0.5 \mathrm{M} \mathrm{NaCl}, 0.02 \mathrm{M} \mathrm{TEA} \mathrm{pH} \mathrm{7.5,} \mathrm{1mM} \mathrm{DTT,} \mathrm{10 \%} \mathrm{glycerol} \mathrm{plus}$

323 mammalian protease inhibitors (Sigma P8340-5ml) and sonicated on ice 5x 10 sec bursts.

324 Lysates was clarified by centrifugation at 35,000G for 40 minutes at $4^{\circ} \mathrm{C}$. Clarified supernatant

325 was then incubated with equilibrated Flag M2 resin (Sigma) for $1 \mathrm{hr}$ on a roller at $4^{\circ} \mathrm{C}$. Flag resin

326 was then subjected to $4 \mathrm{x}$ batch washes with lysis buffer (without mammalian protease

327 inhibitors) with 5 minutes on a roller at $4^{\circ} \mathrm{c}$ between each spin. The resin was then placed into

328 gravity flow column for a final wash and protein was eluted with $100 \mu \mathrm{g} / \mathrm{ml}$ Flag peptide. Flag-

329 Mph1 and Flag-FANCM-FAAP24 complexes were subjected to further purification by ssDNA

330 affinity resin (Sigma): Flag elutions containing FANCM were pooled and diluted to have a final

331 concentration of $100 \mathrm{mM} \mathrm{NaCl}, 20 \mathrm{mM}$ TEA pH7.5, 10\% glycerol, 1mM DTT (buffer B) and added 
332 to $400 \mu \mathrm{l}$ ssDNA resin overnight on a roller at $4^{\circ} \mathrm{C}$. The resin was then placed down gravity flow

333 column and washed with 10CV of buffer B. FANCM-FAAP24 complexes were eluted with buffer

334 B containing $0.5 \mathrm{M} \mathrm{NaCl}$. Proteins were quantified using BSA titrations on SDS-PAGE gels. All

335 proteins were flash frozen in their final buffers and stored at $-80^{\circ} \mathrm{C}$. Topoisomerase I from E.coli

336 and all restriction enzymes were purchased from New England Biolabs.

337 R-loop unwinding assays

338 R-loop unwinding reactions $(10 \mu \mathrm{l})$ contained 1nM of R-loop, $1 \mathrm{mM} \mathrm{ATP}, 2 \mu$ l of protein (protein

339 concentrations stated in main text) in R-loop buffer (6.6mM Tris pH7.5, 3\% glycerol, 0.1mM

340 EDTA, $1 \mathrm{mM} \mathrm{DTT}, 0.5 \mathrm{mM} \mathrm{MgCl}$ ) and incubated at $37^{\circ} \mathrm{C}$ for time as shown in figures. Reactions

341 were stopped by adding $2 \mu \mathrm{l}$ of stop buffer (10mg. $\mathrm{ml}^{-1}$ proteinase $\mathrm{K}(\mathrm{NEB}), 1 \% \mathrm{SDS}$ ) and

342 incubated for $15 \mathrm{~min}$ at $37^{\circ} \mathrm{C} .2 \mu \mathrm{l}$ of $50 \%$ glycerol was added to samples prior to loading onto $1 \%$

343 or $0.8 \%$ agarose TAE gels, run at $100 \mathrm{~V}$ in TAE buffer ( $40 \mathrm{mM}$ Tris, $20 \mathrm{mM}$ acetic acid, $1 \mathrm{mM}$ EDTA)

344 for 60-90 mins. Gels were then crushed between precut biodyene B membranes (Pall) for

345 1hour, exposed overnight to a GE phosphor-screen and imaged on a Typhoo scanner (GE

346 Biosciences). To visualize DNA, agarose gels were post stained with Sybr gold (Thermofisher) 1

347 in 10,000 in TAE.

348 Quantification of R-loop unwinding was performed using Image J and Prism software.

349 Cell based assays

350 HCT116- or FANCM-/- and FANCL-/- derivatives were provided by Lei Li (University of Texas MD

351 Anderson). Cell lines were authenticated by G-banding (St Vincent's Cytogenetics) and

352 maintained in DMEM $+10 \%$ fetal bovine serum at $37^{\prime} \mathrm{C}, 5 \% \mathrm{CO}_{2}$ in a humidified chamber. For

353 drug sensitivity assays, cells were plated in 96-well plates at 1,500 cells/well, then treated $24 \mathrm{hrs}$ 
354 later with various concentrations of topotecan (aka Hycamptin ${ }^{\circledR}$, GSK) or pladienolamide $B$

355 (Calbiochem). After 72hr, survival was measured using sulforhodamine B assay read at 550nm

356 on a EnSpire Plate reader (Perkin Elmer).

357 To measure total cellular R-loop levels, HCT116 cells were treated with drug or vehicle for $4 \mathrm{hr}$.

358 Total genomic DNA was extracted using Isolate II kit (Bioline). $1 \mu \mathrm{g}$ of genomic DNA was slot

359 blotted, using a BioRad Microfiltration apparatus, onto Biodyne B Nylon membrane (Thermo

360 Fisher), which was then air-dried and blocked in Odyssey blocking buffer (LiCor). The membrane

361 was then probed with $0.5 \mu \mathrm{g} / \mathrm{mL}$ S9.6 anti-DNA:RNA monoclonal antibody (produced and

362 purified in house from $\$ 9.6$ hybridoma (ATCC)) and 10ng/ml anti-ssDNA (F7-26, Millipore).

363 Atto800-anti-mouse (LiCor) and Cy5-conjugated anti-IgM antibody (Millipore) were used to

364 visualize the level of DNA:RNA hybrids and total DNA detected by the primary antibodies, and

365 visualized and quantified using Odyssey LiCor dual color imaging system and accompanying

366 software.

368 Author contributions

369 Conceptualization, C.H., J.J.O, and A.J.D.; Methodology, C.H., J.J.O., S.v.T., V.J.M., and A.J.D.;

370 Investigation, all authors.; Writing - Original Draft, C.H. and A.J.D..; Writing - Review \& Editing

371 C.H., J.J.O, E.D. and A.J.D.; Funding Acquisition, A.J.D.; and Supervision, C.H., and A.J.D.

\section{Acknowledgements}

373 We thank members of the Genome Stability Unit for input and discussions, and Jörg Heierhorst,

374 Wayne Crismani and Wojciech Niedzwiedz for comments and suggestions on the manuscript.

375 Thanks to Claus Azzalin for providing telomeric repeat plasmids, Lei Li for providing the HCT116 
bioRxiv preprint doi: https://doi.org/10.1101/248161· this version posted January 15,2018 . The copyright holder for this preprint (which was not certified by peer review) is the author/funder, who has granted bioRxiv a license to display the preprint in perpetuity. It is made available under aCC-BY-NC-ND 4.0 International license.

376 cell lines and Steve West for RecG. AJD is a Victorian Cancer Agency fellow, JJO received

377 scholarship from the Leukaemia Foundation (Australia). This work was funded by National

378 Health and Medical Research Council Australia (grants 1123100 and 1126004), Cancer Council

379 of Victoria, Buxton trust and the Victorian Government's OIS Program. 
380

\section{References}

Arora R, Lee Y, Wischnewski H, Brun CM, Schwarz T, Azzalin CM (2014) RNaseH1 regulates TERRA-telomeric DNA hybrids and telomere maintenance in ALT tumour cells. Nat Commun 5 : 5220 Arudchandran A, Bernstein RM, Max EE (2004) Single-stranded DNA breaks adjacent to cytosines occur during Ig gene class switch recombination. J Immunol 173: 3223-9 Azzalin CM, Reichenbach P, Khoriauli L, Giulotto E, Lingner J (2007) Telomeric repeat containing RNA and RNA surveillance factors at mammalian chromosome ends. Science 318: 798-801 Bachrati CZ, Borts RH, Hickson ID (2006) Mobile D-loops are a preferred substrate for the Bloom's syndrome helicase. Nucleic Acids Research 34: 2269-2279

Bakker ST, van de Vrugt HJ, Rooimans MA, Oostra AB, Steltenpool J, Delzenne-Goette E, van der Wal A, van der Valk $M$, Joenje $H$, te Riele $H$, de Winter JP (2009) Fancm-deficient mice reveal unique features of Fanconi anemia complementation group M. Hum Mol Genet 18: 3484-95 Belotserkovskii BP, Soo Shin JH, Hanawalt PC (2017) Strong transcription blockage mediated by R-loop formation within a G-rich homopurine-homopyrimidine sequence localized in the vicinity of the promoter. Nucleic Acids Res

Berger I, Fitzgerald DJ, Richmond TJ (2004) Baculovirus expression system for heterologous multiprotein complexes. Nature biotechnology 22: 1583-7

Bhatia V, Barroso SI, Garcia-Rubio ML, Tumini E, Herrera-Moyano E, Aguilera A (2014) BRCA2 prevents R-loop accumulation and associates with TREX-2 mRNA export factor PCID2. Nature 511: 362-5

Blackford AN, Schwab RA, Nieminuszczy J, Deans AJ, West SC, Niedzwiedz W (2013) The DNA translocase activity of FANCM protects stalled replication forks. Hum Mol Genet 21: 2005-16 Castella M, Jacquemont C, Thompson EL, Yeo JE, Cheung RS, Huang JW, Sobeck A, Hendrickson EA, Taniguchi T (2015) FANCI Regulates Recruitment of the FA Core Complex at Sites of DNA Damage Independently of FANCD2. PLoS Genet 11: e1005563

Chakraborty P, Grosse F (2011) Human DHX9 helicase preferentially unwinds RNA-containing displacement loops (R-loops) and G-quadruplexes. DNA Repair (Amst) 10: 654-65 Chang EY, Novoa CA, Aristizabal MJ, Coulombe Y, Segovia R, Chaturvedi R, Shen Y, Keong C, Tam AS, Jones SJM, Masson JY, Kobor MS, Stirling PC (2017) RECQ-like helicases Sgs1 and BLM regulate R-loop-associated genome instability. J Cell Biol 216: 3991-4005 Cheok CF, Wu L, Garcia PL, Janscak P, Hickson ID (2005) The Bloom's syndrome helicase promotes the annealing of complementary single-stranded DNA. Nucleic Acids Res 33: 3932-41 Collis SJ, Ciccia A, Deans AJ, Horejsí Z, Martin JS, Maslen SL, Skehel JM, Elledge SJ, West SC, Boulton SJ (2008) FANCM and FAAP24 function in ATR-mediated checkpoint signaling independently of the Fanconi anemia core complex. Mol Cell 32: 313-24 Coulthard R, Deans A, Swuec P, Bowles M, Costa A, West S, Costa A, McDonald NQ (2013) Architecture and DNA recognition elements of the Fanconi anemia FANCM-FAAP24 complex. Structure 21: 1648-1658 Crismani W, Girard C, Froger N, Pradillo M, Santos JL, Chelysheva L, Copenhaver GP, Horlow C, Mercier R (2012) FANCM limits meiotic crossovers. Science 336: 1588-90

Deans AJ, West SC (2009) FANCM connects the genome instability disorders Bloom's Syndrome and Fanconi Anemia. Mol Cell 36: 943-53 
423 Deans AJ, West SC (2011) DNA interstrand crosslink repair and cancer. Nat Rev Cancer 11: 46780

El Hage A, French SL, Beyer AL, Tollervey D (2010) Loss of Topoisomerase I leads to R-loopmediated transcriptional blocks during ribosomal RNA synthesis. Genes Dev 24: 1546-58 Garcia-Rubio ML, Perez-Calero C, Barroso SI, Tumini E, Herrera-Moyano E, Rosado IV, Aguilera A (2015) The Fanconi Anemia Pathway Protects Genome Integrity from R-loops. PLoS Genet 11: e1005674 Gari K, Décaillet C, Delannoy M, Wu L, Constantinou A (2008a) Remodeling of DNA replication structures by the branch point translocase FANCM. Proc Natl Acad Sci USA Gari K, Decaillet C, Stasiak AZ, Stasiak A, Constantinou A (2008b) The Fanconi anemia protein FANCM can promote branch migration of Holliday junctions and replication forks. Mol Cell 29: 141-8

Ginno PA, Lim YW, Lott PL, Korf I, Chedin F (2013) GC skew at the 5' and 3' ends of human genes links R-loop formation to epigenetic regulation and transcription termination. Genome Res 23: 1590-600 characteristic of unmethylated human CpG island promoters. Mol Cell 45: 814-25 Hamperl S, Bocek MJ, Saldivar JC, Swigut T, Cimprich KA (2017) Transcription-Replication Conflict Orientation Modulates R-Loop Levels and Activates Distinct DNA Damage Responses. Cell 170: 774-786 e19 Helmrich A, Ballarino M, Tora L (2011) Collisions between replication and transcription complexes cause common fragile site instability at the longest human genes. Mol Cell 44: 96677

Henricksen LA, Umbricht CB, Wold MS (1994) Recombinant replication protein A: expression, complex formation, and functional characterization. J Biol Chem 269: 11121-32 Hill SJ, Rolland T, Adelmant G, Xia X, Owen MS, Dricot A, Zack TI, Sahni N, Jacob Y, Hao T, McKinney KM, Clark AP, Reyon D, Tsai SQ, Joung JK, Beroukhim R, Marto JA, Vidal M, Gaudet S, Hill DE et al. (2014) Systematic screening reveals a role for BRCA1 in the response to transcription-associated DNA damage. Genes Dev 28: 1957-75 Hong X, Cadwell GW, Kogoma T (1995) Escherichia coli RecG and RecA proteins in R-loop formation. EMBO J 14: 2385-92 Huertas P, Aguilera A (2003) Cotranscriptionally formed DNA:RNA hybrids mediate transcription elongation impairment and transcription-associated recombination. Mol Cell 12: 711-21 Lee M, Hills M, Conomos D, Stutz MD, Dagg RA, Lau LM, Reddel RR, Pickett HA (2014) Telomere extension by telomerase and ALT generates variant repeats by mechanistically distinct processes. Nucleic Acids Res 42: 1733-46 Madireddy A, Kosiyatrakul ST, Boisvert RA, Herrera-Moyano E, Garcia-Rubio ML, Gerhardt J, Vuono EA, Owen N, Yan Z, Olson S, Aguilera A, Howlett NG, Schildkraut CL (2016) FANCD2 Facilitates Replication through Common Fragile Sites. Mol Cell 64: 388-404 Martadinata H, Phan AT (2013) Structure of human telomeric RNA (TERRA): stacking of two Gquadruplex blocks in $\mathrm{K}(+)$ solution. Biochemistry 52: 2176-83 McGlynn P, Al-Deib AA, Liu J, Marians KJ, Lloyd RG (1997) The DNA replication protein PriA and the recombination protein RecG bind D-loops. J Mol Biol 270: 212-21 
Meetei AR, Medhurst AL, Ling C, Xue Y, Singh TR, Bier P, Steltenpool J, Stone S, Dokal I, Mathew CG, Hoatlin M, Joenje H, de Winter JP, Wang W (2005) A human ortholog of archaeal DNA repair protein Hef is defective in Fanconi anemia complementation group M. Nat Genet 37: 958-63 Mosedale G, Niedzwiedz W, Alpi A, Perrina F, Pereira-Leal JB, Johnson M, Langevin F, Pace P, Patel KJ (2005) The vertebrate Hef ortholog is a component of the Fanconi anemia tumorsuppressor pathway. Nat Struct Mol Biol 12: 763-71 Muller B, West SC (1994) Processing of Holliday junctions by the Escherichia coli RuvA, RuvB, RuvC and RecG proteins. Experientia 50: 216-22 Nakamura H, Oda Y, Iwai S, Inoue H, Ohtsuka E, Kanaya S, Kimura S, Katsuda C, Katayanagi K, Morikawa K, et al. (1991) How does RNase H recognize a DNA.RNA hybrid? Proc Natl Acad Sci U S A 88: 11535-9 Nguyen HD, Yadav T, Giri S, Saez B, Graubert TA, Zou L (2017) Functions of Replication Protein A as a Sensor of R Loops and a Regulator of RNaseH1. Mol Cell 65: 832-847.e4 Nguyen TV, Riou L, Aoufouchi S, Rosselli F (2014) Fanca deficiency reduces A/T transitions in somatic hypermutation and alters class switch recombination junctions in mouse $B$ cells. J Exp Med 211: 1011-8 Hybrids Are Required for Efficient Double-Strand Break Repair. Cell 167: 1001-1013.e7 Pan X, Drosopoulos WC, Sethi L, Madireddy A, Schildkraut CL, Zhang D (2017) FANCM, BRCA1, and BLM cooperatively resolve the replication stress at the ALT telomeres. Proc Natl Acad Sci U $S A$

Popuri V, Bachrati CZ, Muzzolini L, Mosedale G, Costantini S, Giacomini E, Hickson ID, Vindigni A (2008) The Human RecQ helicases, BLM and RECQ1, display distinct DNA substrate specificities. J Biol Chem 283: 17766-76 NA, Yasui DH, Chedin F, LaSalle JM (2013) R-loop formation at Snord116 mediates topotecan inhibition of Ube3a-antisense and allele-specific chromatin decondensation. Proc Natl Acad Sci U S A 110: 13938-43 Prakash R, Satory D, Dray E, Papusha A, Scheller J, Kramer W, Krejci L, Klein H, Haber JE, Sung P, Ira G (2009) Yeast Mph1 helicase dissociates Rad51-made D-loops: implications for crossover control in mitotic recombination. Genes Dev 23: 67-79 Roy D, Yu K, Lieber MR (2008) Mechanism of R-Loop Formation at Immunoglobulin Class Switch Sequences. Molecular and Cellular Biology 28: 50-60 Scheller J, Schurer A, Rudolph C, Hettwer S, Kramer W (2000) MPH1, a yeast gene encoding a DEAH protein, plays a role in protection of the genome from spontaneous and chemically induced damage. Genetics 155: 1069-81 Schrader CE, Guikema JE, Linehan EK, Selsing E, Stavnezer J (2007) Activation-induced cytidine deaminase-dependent DNA breaks in class switch recombination occur during $\mathrm{G} 1$ phase of the cell cycle and depend upon mismatch repair. J Immunol 179: 6064-71 Schwab RA, Nieminuszczy J, Shah F, Langton J, Lopez Martinez D, Liang CC, Cohn MA, Gibbons 508 RJ, Deans AJ, Niedzwiedz W (2015) The Fanconi Anemia Pathway Maintains Genome Stability by Coordinating Replication and Transcription. Mol Cell 60: 351-61 
Shin JH, Kelman Z (2006) The replicative helicases of bacteria, archaea, and eukarya can unwind RNA-DNA hybrid substrates. J Biol Chem 281: 26914-21 Singh TR, Bakker ST, Agarwal S, Jansen M, Grassman E, Godthelp BC, Ali AM, Du CH, Rooimans MA, Fan Q, Wahengbam K, Steltenpool J, Andreassen PR, Williams DA, Joenje H, de Winter JP, Meetei AR (2009) Impaired FANCD2 monoubiquitination and hypersensitivity to camptothecin uniquely characterize Fanconi anemia complementation group M. Blood 114: 174-80 Singleton MR, Scaife S, Raven ND, Wigley DB (2001) Crystallization and preliminary X-ray analysis of RecG, a replication-fork reversal helicase from Thermotoga maritima complexed with a three-way DNA junction. Acta crystallographica Section D, Biological crystallography 57: 518 1695-6 Sollier J, Cimprich KA (2015) Breaking bad: R-loops and genome integrity. Trends Cell Biol 25: 514-22 Sollier J, Stork CT, Garcia-Rubio ML, Paulsen RD, Aguilera A, Cimprich KA (2014) Transcriptioncoupled nucleotide excision repair factors promote R-loop-induced genome instability. Mol Cell 56: 777-85 Stork CT, Bocek M, Crossley MP, Sollier J, Sanz LA, Chedin F, Swigut T, Cimprich KA (2016) Cotranscriptional R-loops are the main cause of estrogen-induced DNA damage. eLife 5 Sun W, Nandi S, Osman F, Ahn JS, Jakovleska J, Lorenz A, Whitby MC (2008) The FANCM ortholog Fml1 promotes recombination at stalled replication forks and limits crossing over during DNA double-strand break repair. Mol Cell 32: 118-28 Sutherland JH, Tse-Dinh YC (2010) Analysis of RuvABC and RecG involvement in the escherichia coli response to the covalent topoisomerase-DNA complex. J Bacteriol 192: 4445-51 Szczelkun MD, Tikhomirova MS, Sinkunas T, Gasiunas G, Karvelis T, Pschera P, Siksnys V, Seidel $\mathrm{R}$ (2014) Direct observation of R-loop formation by single RNA-guided Cas9 and Cascade effector complexes. Proc Natl Acad Sci U S A 111: 9798-803 Vincent SD, Mahdi AA, Lloyd RG (1996) The RecG branch migration protein of Escherichia coli dissociates R-loops. J Mol Biol 264: 713-21 Wan Y, Zheng X, Chen H, Guo Y, Jiang H, He X, Zhu X, Zheng Y (2015) Splicing function of mitotic regulators links R-loop-mediated DNA damage to tumor cell killing. J Cell Biol 209: 235-46 Wang Y, Leung Justin W, Jiang Y, Lowery Megan G, Do H, Vasquez Karen M, Chen J, Wang W, Li $\mathrm{L}$ (2013) FANCM and FAAP24 Maintain Genome Stability via Cooperative as Well as Unique Functions. Molecular cell 49: 997-1009 Whitby MC (2010) The FANCM family of DNA helicases/translocases. DNA Repair (Amst) 9: 22436 Drosophila topoisomerase III . Proceedings of the National Academy of Sciences 99: 7974-7979 Xue Y, Li Y, Guo R, Ling C, Wang W (2008) FANCM of the Fanconi anemia core complex is required for both monoubiquitination and DNA repair. Hum Mol Genet Yuce O, West SC (2013) Senataxin, defective in the neurodegenerative disorder ataxia with 


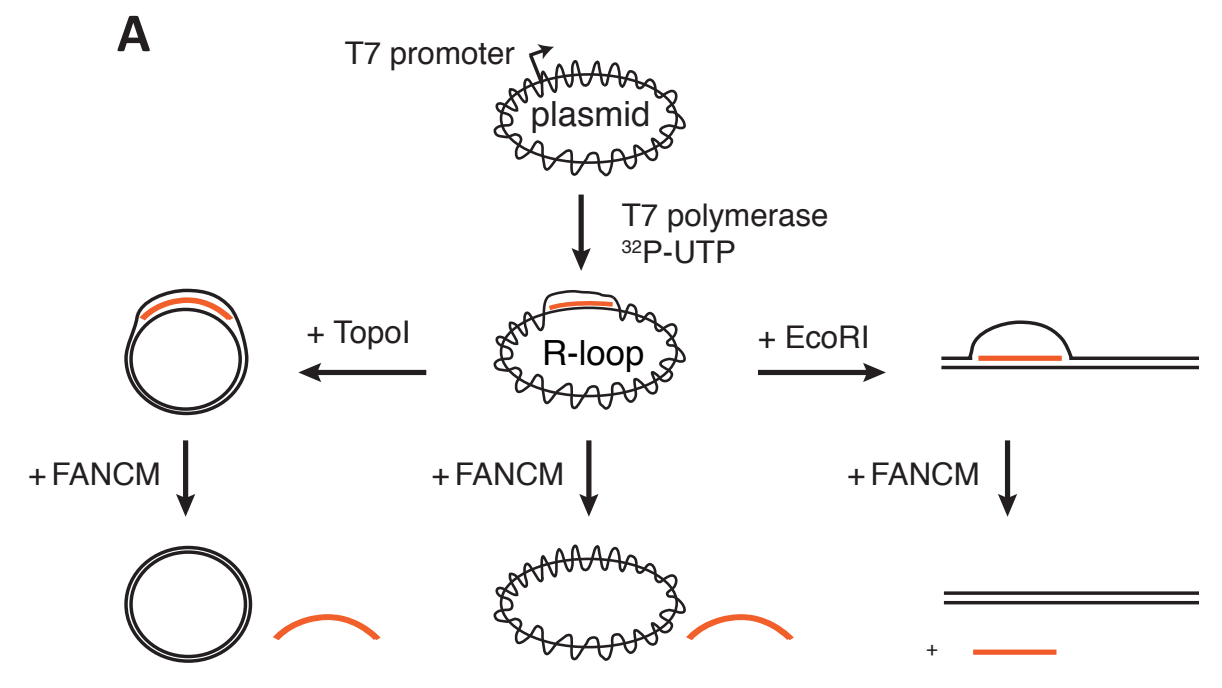

B

C
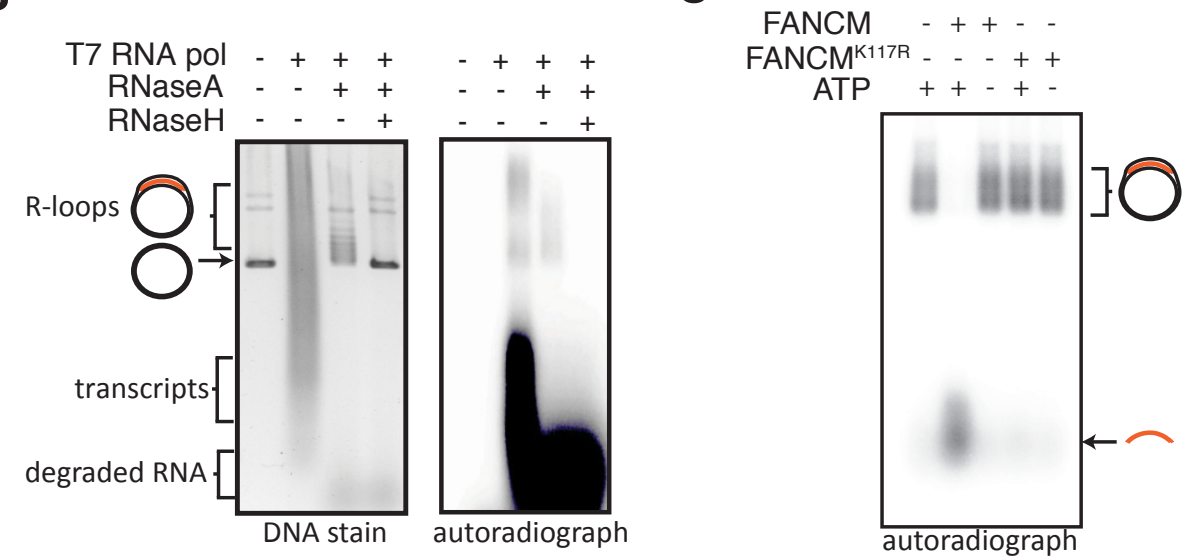

Figure 1: Generation of co-transcriptional R-loops in vitro and their processing by FANCM-FAAP24. A) Schematic of method used to generate and unwind R-loops of different topological states. DNA is coloured black and RNA orange. B) Plasmid based R-loops observed by gel electrophoresis. Sybr gold stain of plasmid DNA molecules reveals the topological changes to the plasmid DNA upon R-loop formation. Right panel is an autoradiograph identifying the 32P-UTP incorporation into R-loop, transcripts or post-RNAse treatment. C) Autoradiograph showing FANCM-FAAP24 (1nM) unwinding purified R-loops $(1 \mathrm{nM})$ in an ATP dependent manner. FANCM ${ }^{\mathrm{K} 117 \mathrm{R}}$ is a translocase activity deficient mutant. 
A

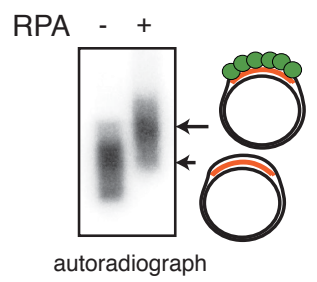

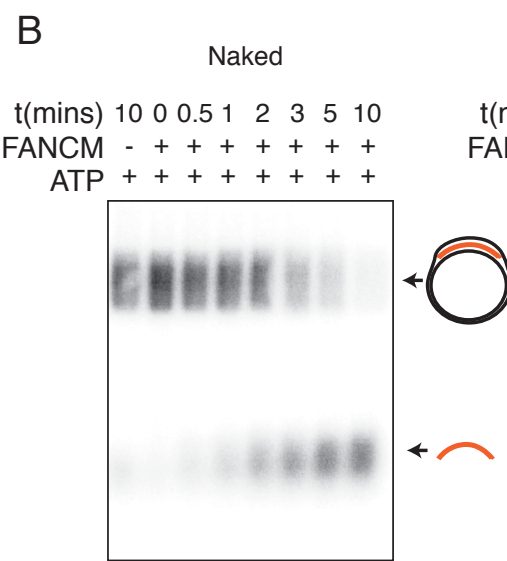

autoradiograph
RPA-coated

$t$ (mins) 1000.5123510

FANCM -+++++++ ATP ++++++++

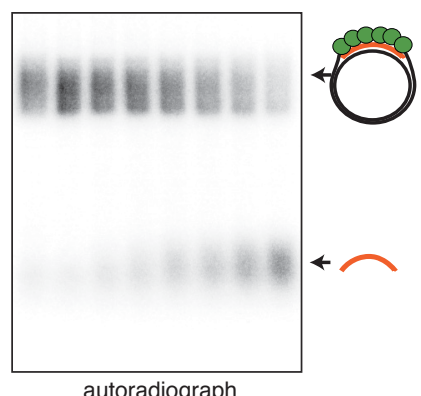

autoradiograph

C

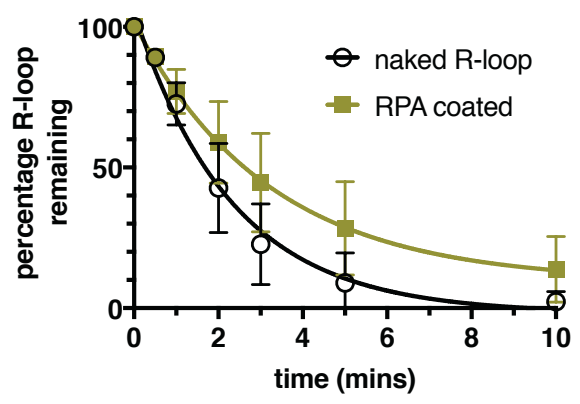

Figure 2: FANCM-FAAP24 acts on protein coated R-loops.

A) Autoradiograph of an EMSA showing RPA bound to plasmid based R-loops. B) Representative Autoradiographs of time course assays of FANCM $(0.25 \mathrm{nM})$ activity on naked R-loops ( $1 \mathrm{nM}$, left panel) versus RPA coated R-loops ( $1 \mathrm{nM}$ right panel) C) Quantification of unwinding activity ( \pm stderr) from $n>3$ experiments. 


\section{A}

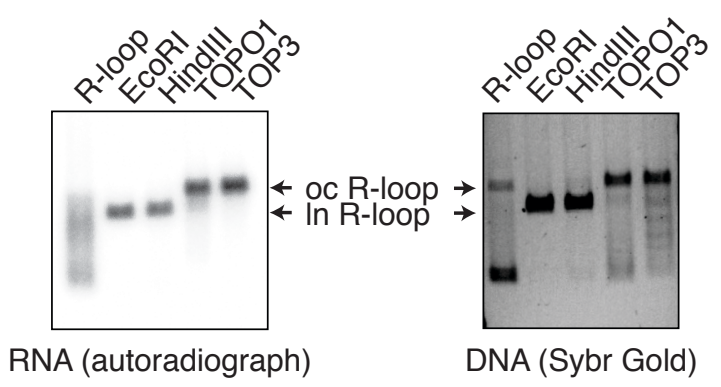

B

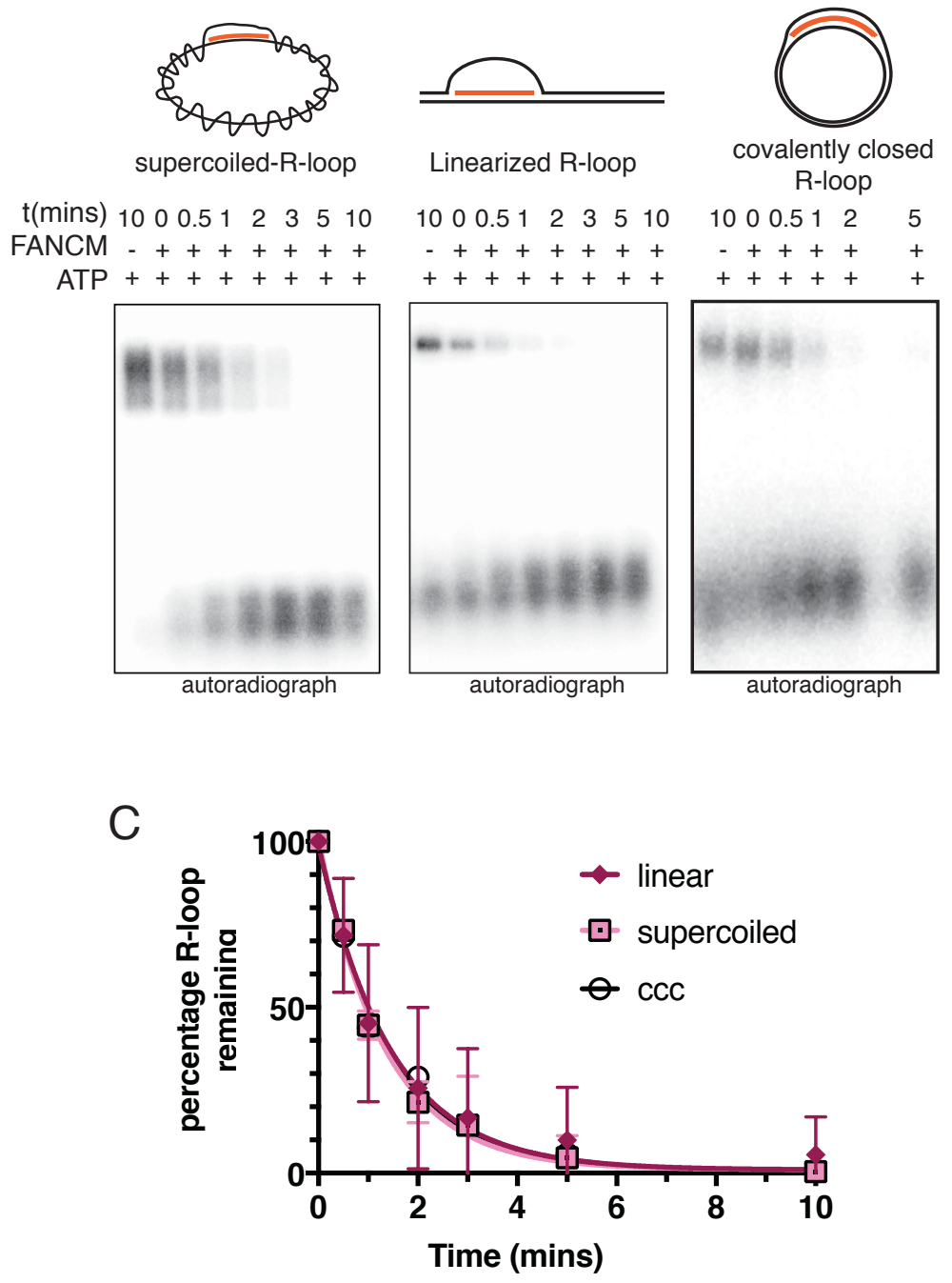

\section{Figure 3: FANCM unwinds R-loops with different DNA topologies}

A) Characterization of topological isoforms of plasmid based R-loops after generation of linear form by restriction enzyme digestion by EcoRI or HindIII, or covalently closed circle form (ccc) by

topoisomerases 1 or III treatment. Left panel is an autoradiograph depicting the RNA molecules. The right panel is sybr gold stain of the DNA molecules. B) Autoradiographs of time course assays of plasmid (left panel) versus linear (middle panel) based R-loops. The graph is the average $(n=3) \%$ of R-loop unwound (y-axis) of each time point (x-axis) with standard error bars. Final concentrations of R-loops and FANCM for these assays was $1 \mathrm{nM}$ and $0.25 \mathrm{nM}$ respectively. 
bioRxiv preprint doi: https://doi.org/10.1101/248161; this version posted January 15,2018 . The copyright holder for this preprint (which was not certified by peer review) is the author/funder, who has granted bioRxiv a license to display the preprint in perpetuity. It is made available under aCC-BY-NC-ND 4.0 International license.
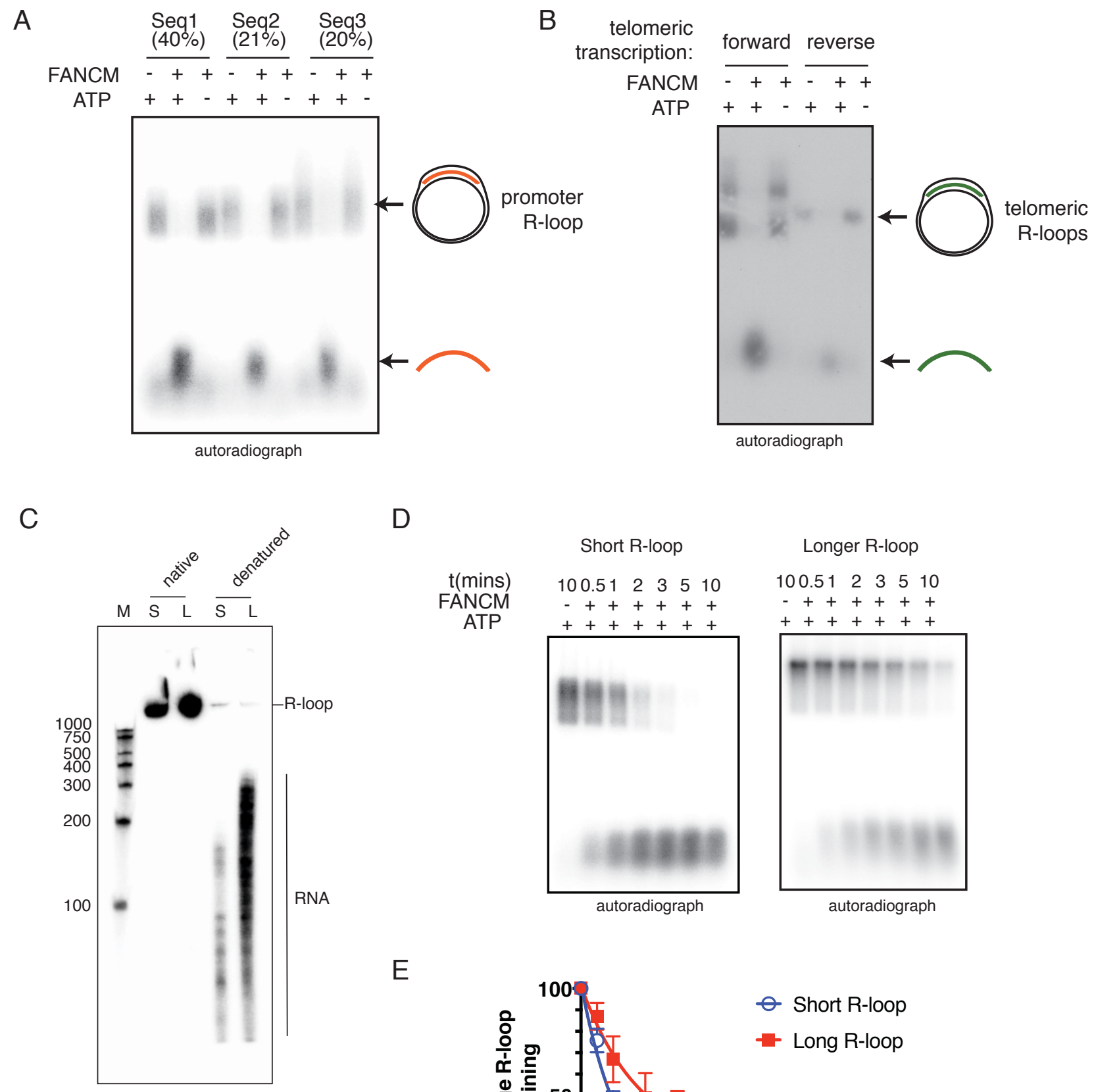

D
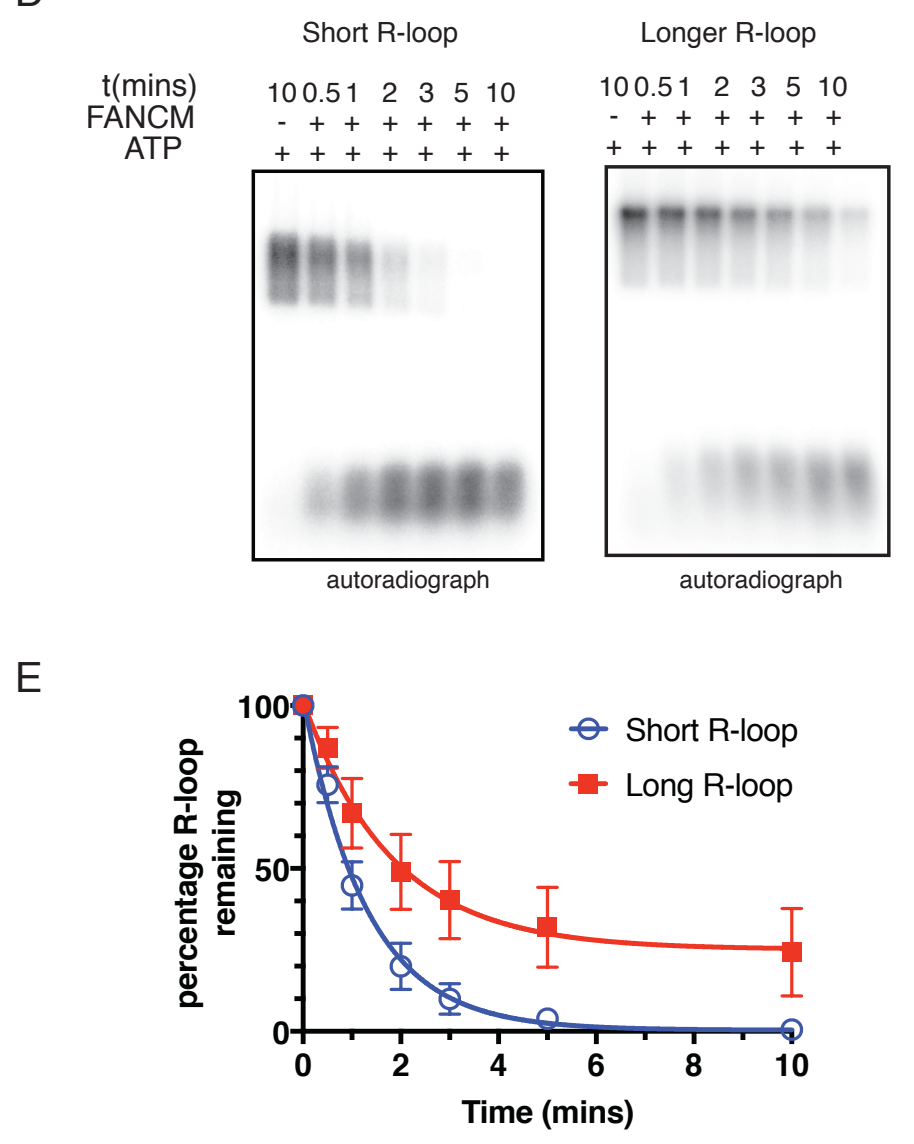

Figure 4: FANCM-FAAP24 can process R-loops irrespective of sequence, length or genomic origin. A) R-loop processing assay with three independently derived R-loop forming sequences. The GC skew \% of each sequence is indicated in brackets above the autoradiograph. B) $\mathrm{R}$-loops can be formed by in vitro transcription in a forward or reverse direction through a $1.4 \mathrm{~kb}$ telomeric repeat sequence. FANCM:FAAP24 was tested against both products. C) R-loops of similar sequence but different length were generated (see materials and methods) and shown to produce trapped RNA species of different sizes on a PAGE gel. Short (S) and long (L) plasmid based R-loops are shown in native or denatured states. D-E) Substrates from C were incubated in a representative timecourse with FANCM:FAAP24 and R-loop remaining plotted from an average of 3 experiments ( \pm stderr). 


\section{A}

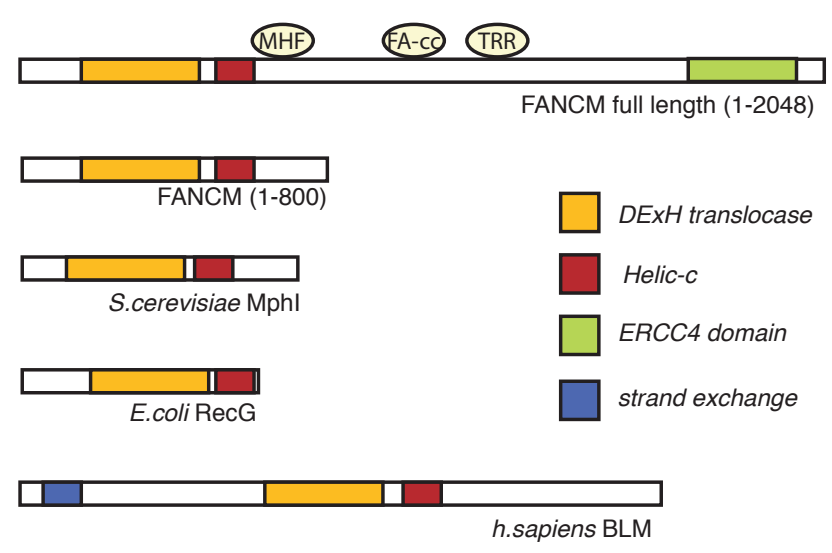

B

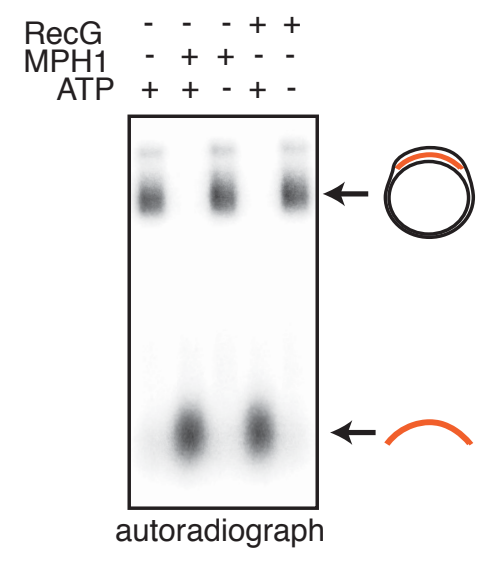

C

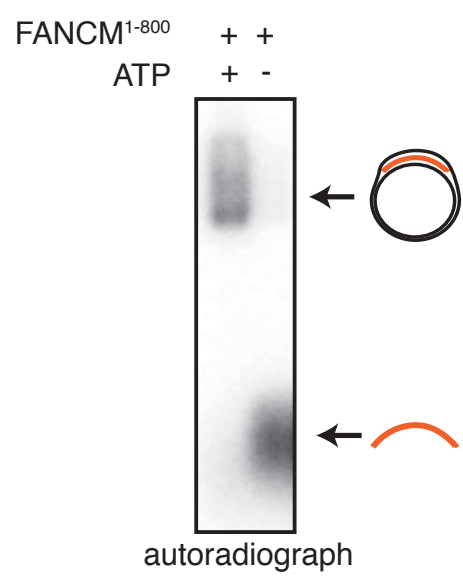

D

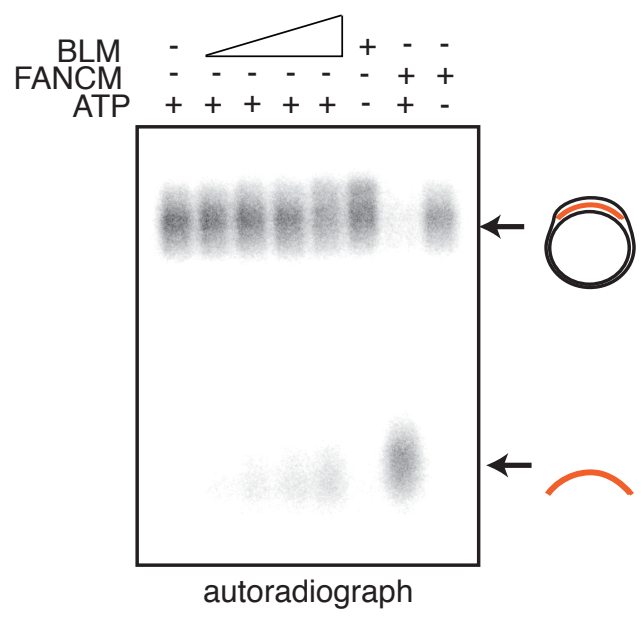

Figure 5 Conserved action of FANCM-like proteins in R-loop metabolism.

A) Domain organization of FANCM orthologs, and BLM showing conserved domains. For FANCM, interaction sites are shown for: $\mathrm{MHF}=\mathrm{MHF} 1 / 2$ complex, FAcc=Fanconi anemia core complex, TRR=Top3A-RMI1-RMI2 complex. B) MPH1 and RecG (1nM) unwind plasmid based R-loops in an ATP dependent manner, in a 10 minute reaction. C) FANCM (1nM) 1-800 retains the ability to unwind R-loops in vitro. D) Autoradiograph showing BLM unwinding plasmid based R-loops is ATP dependent but less efficient then FANCM. The concentrations of BLM used was 1, 10, 20, 40, 40nM (lane2-6) or 1nM for FANCM-FAAP24 (lane7-8) . 
A
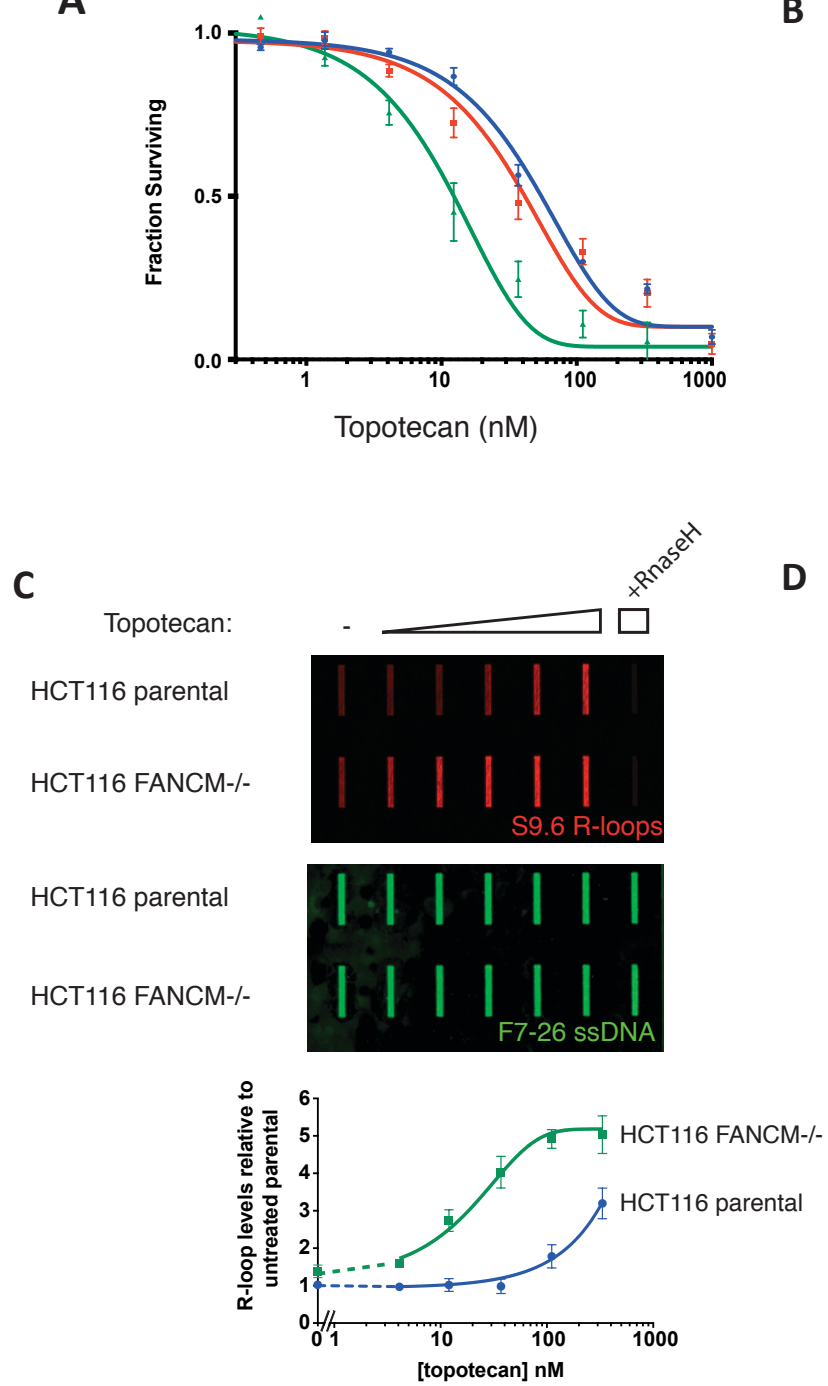

B

D

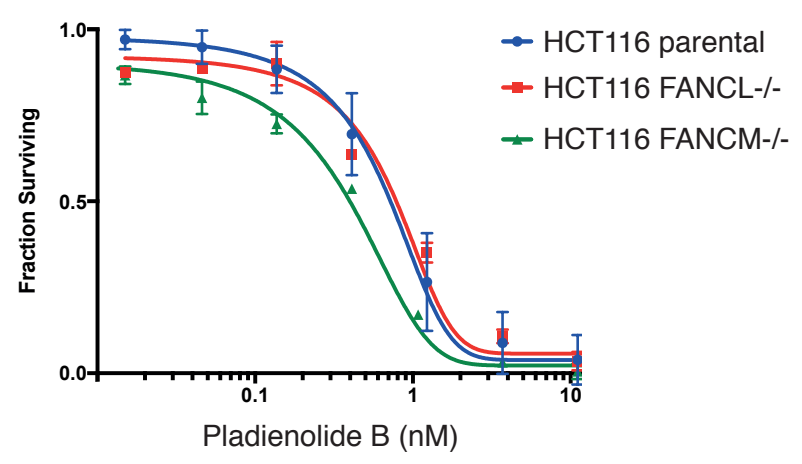
Pladienolide B: HCT116 parental HCT116 FANCM-/HCT116 parental HCT116 FANCM-/-
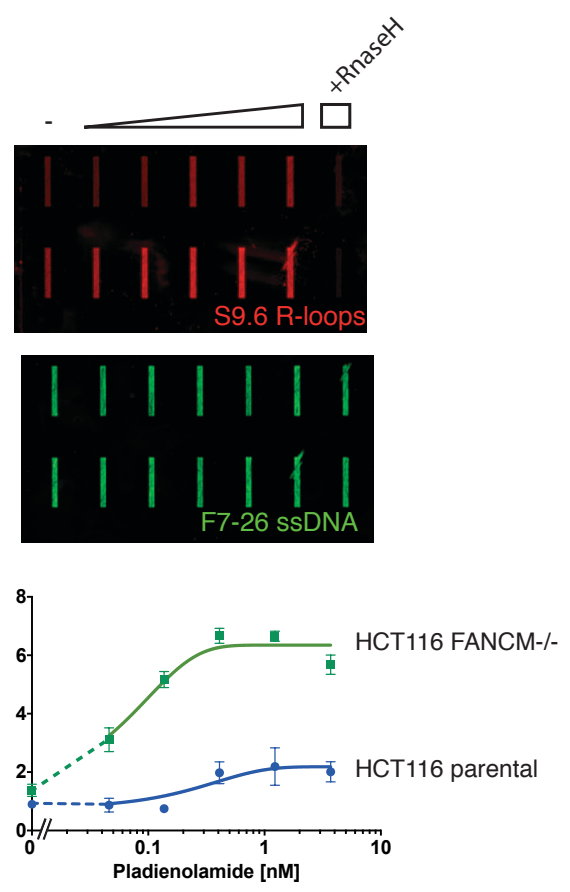

\section{Figure 6 FANCM deficient cells are sensitive to R-loop stabilizing compounds}

A-B) Dose response curves of parental and FANCM-/- HCT116 cell lines exposed to topotecan (left) or pladienolide B (right) for 72hours and stained with sulforhodamine B. C-D) Total R-loop levels measured by slot blotting of HCT116 genomic DNA extracted after increasing dose of topotecan or pladienolide B. Blots were probed with S9.6 anti-DNA:RNA hybrid or F7-26 anti-DNA, far-red secondary antibodies and detected by LiCor Odyssey imaging. RNaseH treated genomic DNA was used as a control for S9.6 DNA:RNA hybrid specificity. Quantification of S9.6 verses F7-26 slot blot signal from 3 experiments +/- sterr is shown in graphed form. 

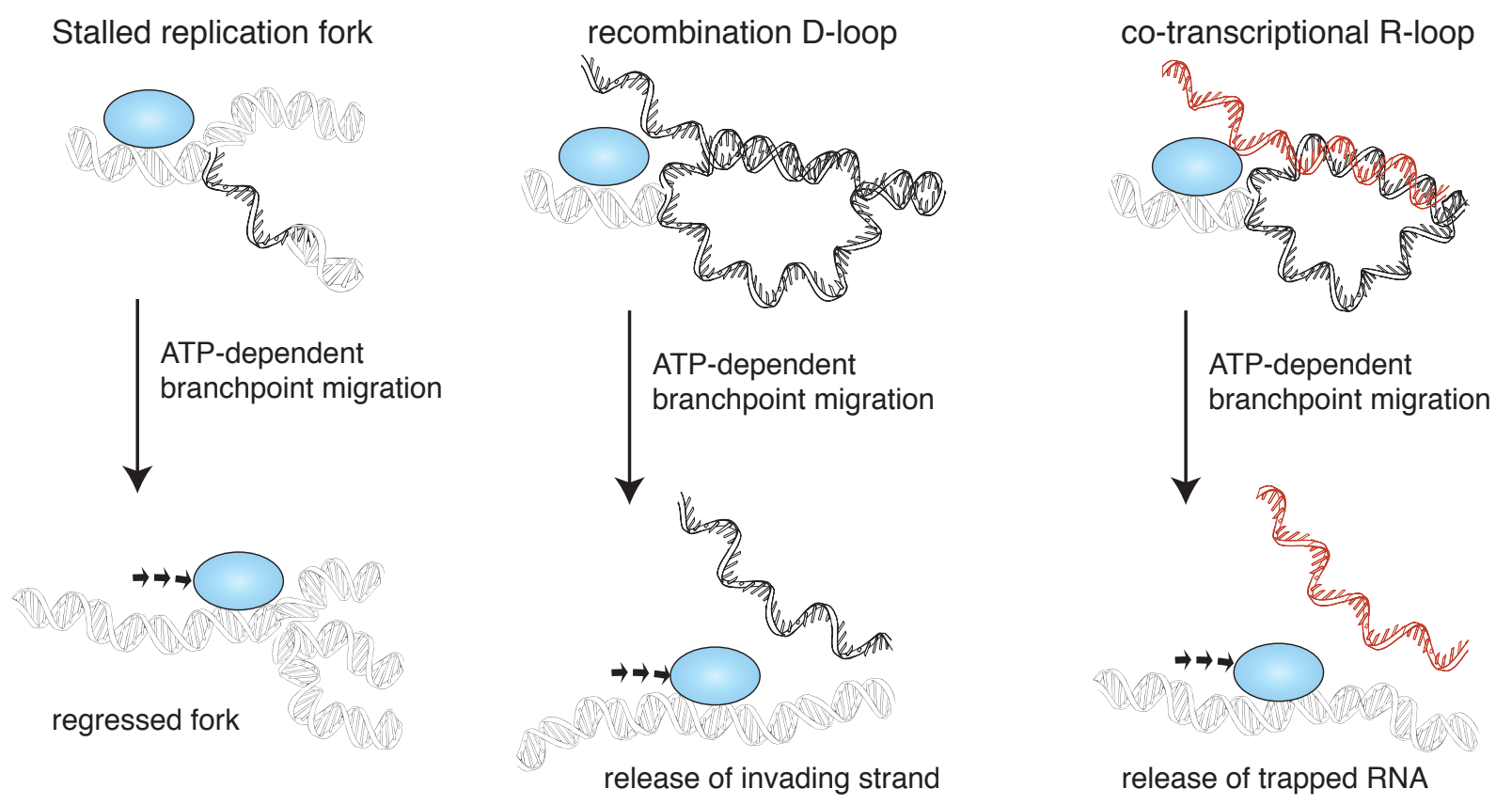

Figure 7 Model for FANCM-family-mediated maintenance of genome stability by a common mechanism of branchpoint translocation:

Branchpoint translocation is indicated for 3 different DNA structures associated with genome instability. FANCM/Mph1/RecG or other family member (blue sphere in cartoon) binds specifically to junction structure in DNA. This engages the motor activity of the enzyme, to continuously push the junction. For a stalled replication fork (left) this leads to formation of a regressed fork, as the nascent DNA strands anneal. For a D-loop or R-loop, branchpoint migration leads to displacement of a ssDNA or RNA molecule respectively. 